\title{
Effect of frame design and veneering material on biomechanical behavior of zirconia dental crowns veneered with overpressing ceramics
}

\author{
Liliana POROJAN ${ }^{1}$, Florin TOPALĂ ${ }^{2}$, Sorin POROJAN³ and Cristina SAVENCU ${ }^{1}$ \\ ${ }^{1}$ Department of Dental Prostheses Technology, School of Dentistry, Victor Babeş University of Medicine and Pharmacy, 9 Revolutiei 1989 Blv., \\ 300041 Timişoara, Romania \\ ${ }^{2}$ Department of Dental Prosthodontics, School of Dentistry, Victor Babeş University of Medicine and Pharmacy, 9 Revolutiei 1989 Blv., 300041 \\ Timişoara, Romania \\ ${ }^{3}$ Department of Oral Rehabilitation, School of Dentistry, Victor Babeş University of Medicine and Pharmacy, 9 Revolutiei 1989 Blv., 300041 Timişoara, \\ Romania \\ Corresponding author, Liliana POROJAN; E-mail: lilianasandu@gmail.com, sliliana@umft.ro
}

\begin{abstract}
The objective of this investigation was to compare alternative framework designs of molar zirconia crowns veneered with various overpressing ceramics and to predict the biomechanical behavior based on the stress evaluation. The hypothesis of the study is that the zirconia framework design and type of the veneering material, using the same technological procedure, may influence the biomechanical behavior of the restorations. Three geometric models with differential coping designs (uniform thickness, cutback and buccal reduction) were developed and two types of hot-pressed ceramics (leucite and lithium disilicate reinforced) were analyzed for the veneers. Using finite element analysis (FEA), maximum principle stresses were recorded in the tooth structures and in the restorations for all the developed designs. Results led to the conclusion that the hypothesis was accepted.
\end{abstract}

Keywords: Dental crowns, High-strength ceramics, Pressed ceramics, Stresses, Finite element analysis

\section{INTRODUCTION}

Since the introduction of zirconia in dentistry, the initial euphoric attitude towards this material and all-ceramic restorations has been relativized by the increased number of adhesive (delamination) and cohesive (chipping) failures of the veneer material compared to metal-ceramic restorations ${ }^{1-4)}$.

The trend for development of high-strength ceramics and its use in posterior areas have been a field of constant investigation $^{5}$. Yttria-Stabilized Tetragonal Zirconia Polycrystals (Y-TZP) were introduced as a core ceramic in attempt to reduce restoration bulk fracture. Their high mechanical properties have resulted in successful use of Y-TZP as a core ceramic in short- and mediumterm clinical studies, where framework fractures were seldom reported ${ }^{4,6)}$. While Y-TZP provides strength, the clinical success of these restorations has been hampered by fractures within the veneering porcelain. Therefore, attempts to improve the performance of the veneering porcelain on Y-TZP restorations considering their multifactorial essence are warranted. To date, no study has investigated the effect of core/framework designs fabricated by different veneering techniques in a standardized and controlled model ${ }^{7}$.

When the first CAD/CAM (computer-aided design and computer-aided manufacturing) systems were brought to the market, the majority of the software systems did not allow core design modifications. Excessive veneer layer thickness was created because of

Color figures can be viewed in the online issue, which is available at J-STAGE.

Received Mar 9, 2016: Accepted Sep 28, 2016

doi:10.4012/dmj.2016-096 JOI JST.JSTAGE/dmj/2016-096 the uniform configuration of the zirconia cores and the need to generate an anatomically correct $\mathrm{crown}^{8}$. As a result, zirconia framework design modifications, derived from the metal-ceramic technique were attempted ${ }^{9,10)}$.

Modification of veneering porcelain application techniques have been another attempt to overcome cohesive failure ${ }^{11)}$. Ceramic ingots for pressing veneering ceramics onto zirconia were developed aiming to combine the advantages of the established press technology with the high strength of the zirconia substrate. The clinical performance of pressable veneering ceramics for zirconia cores has been questioned but not yet fully investigated in controlled clinical trials ${ }^{12-177}$.

The complex and patient unique geometry of posterior all-ceramic dental crowns represents a particularly interesting set of challenges for understanding stress concentration and damage evolution to fracture in response to loading ${ }^{7}$.

Crown geometry plays a pivotal role in fatigue behavior. Therefore, the CAD/CAM fabrication process of zirconia substructures and the corresponding veneering techniques, gains importance. As the veneering ceramic material is weak compared to the high-strength core material the veneering ceramic is prone to fail at low loads during the evolution of complex tensile fields in function ${ }^{18}$.

Designs for restorations created using CAD/ CAM (computer aided designed/computer aided manufactured) are digitally available and more amenable to analysis of stresses ${ }^{19}$. The prediction of which designs will fail is more achievable. However, little information is available regarding the behavior 
of customized coping designs compared to conventional $\operatorname{design}^{20)}$. Stress analysis is a useful tool for predicting the physical responses restored teeth, for example, the most likely fracture location. Much has been reported on the magnitude and distribution of stress associated with various types of restorations ${ }^{21,22)}$. Finite element analysis (FEA) has been widely used in the last few decades to understand and predict biomechanical phenomena ${ }^{23)}$. Most studies evaluated equivalent stresses in the components ${ }^{24}$, but the brittle behavior of ceramic materials led us to use the principal stresses.

A good understanding of theories of failure is imperative in the design of dental restorations. Biomedical studies frequently use FEA to predict the behavior of prosthetic restored teeth. Different studies found that failure by fracture was driven by deformation, and strain-based criteria can well predict fracture sites. These findings may cause us to reconsider the use of stress-based criteria in evaluating the mechanical behavior of all-ceramic systems and expose the need to use the maximum principle stress induced in such brittle materials.

According to the maximum principal stress theory ${ }^{25)}$ failure will occur when the maximum principal stress induced in a material under complex load reaches the value of the maximum stress at elastic limit in simple tension. This theory is approximately correct for brittle materials generally ${ }^{26)}$. In brittle materials, the failure or rupture still occurs due to separation of atomic planes. However, the high value of stress required is provided locally by stress concentration caused by small preexisting cracks or flaws in the material because they are susceptible to slow crack growth $(\mathrm{SCG})^{27,28)}$. Slow crack growth in bioceramics is attributed to stress assisted corrosion at the crack tip, or any pre-existing defect in the ceramic and is subject of important research in the ceramic field ${ }^{28)}$.

The objective of this investigation was to compare alternative framework designs of molar zirconia crowns veneered with various overpressing ceramics and to predict the biomechanical behavior of the prosthetic restored teeth based on the stress evaluation.

The hypothesis of the study is that the zirconia framework design and type of the veneering material, using the same technological procedure, may influence the biomechanical behavior of the restorations.

\section{MATERIALS AND METHODS}

For the experimental evaluations, a maxillary first molar was chosen. A nonparametric modeling software Blender 2.57b (Stichting Blender Foundation, Amsterdam, Netherlands) was used to obtain the 3D tooth shape. The collected data were used to construct three dimensional models using Rhinoceros (McNeel North America, Seattle, WA, USA) NURBS (Nonuniform Rational B-Splines) modeling program. Beginning from the anatomic contour of the crown, the tooth was prepared for all-ceramic bilayered crowns with a $0.7-0.8 \mathrm{~mm}$ chamfer margin. The occlusal surface was then reduced by $1.5-2 \mathrm{~mm}$. The axial walls were prepared with $6^{\circ}$ of inclination.

Three geometric models with differential coping designs were developed, framework designs suggested by the soft of the CAD/CAM system Cercon Art 3.2 (Degudent, Hanau, Germany). First, a uniform thickness of $0.5 \mathrm{~mm}$ was chosen for the framework. Second, a cutback design was prepared as same as for metalceramic crowns in order to obtain uniform, adequate thickness and support for the veneering ceramics. Third, a reduction of the framework was made only in the buccal area, in order to achieve aesthetics (Fig. 1). It was assumed in the study that prosthetic crowns were made of zirconia-based ceramic veneered with overpressing leucite IPS Empress (Ivoclar Vivadent, Schaan, Liechtenstein) and lithium disilicate reinforced ceramics IPS Empress 2 (Ivoclar Vivadent). For all cases a digital model of the bilayer crown was designed to occupy the space between the original tooth form and the prepared tooth form.

The geometric models were imported in the finite element analysis software ANSYS (ANSYS, Canonsburg, PA, USA) and meshed. To perform calculations, each tooth model was divided into a structural solid elements

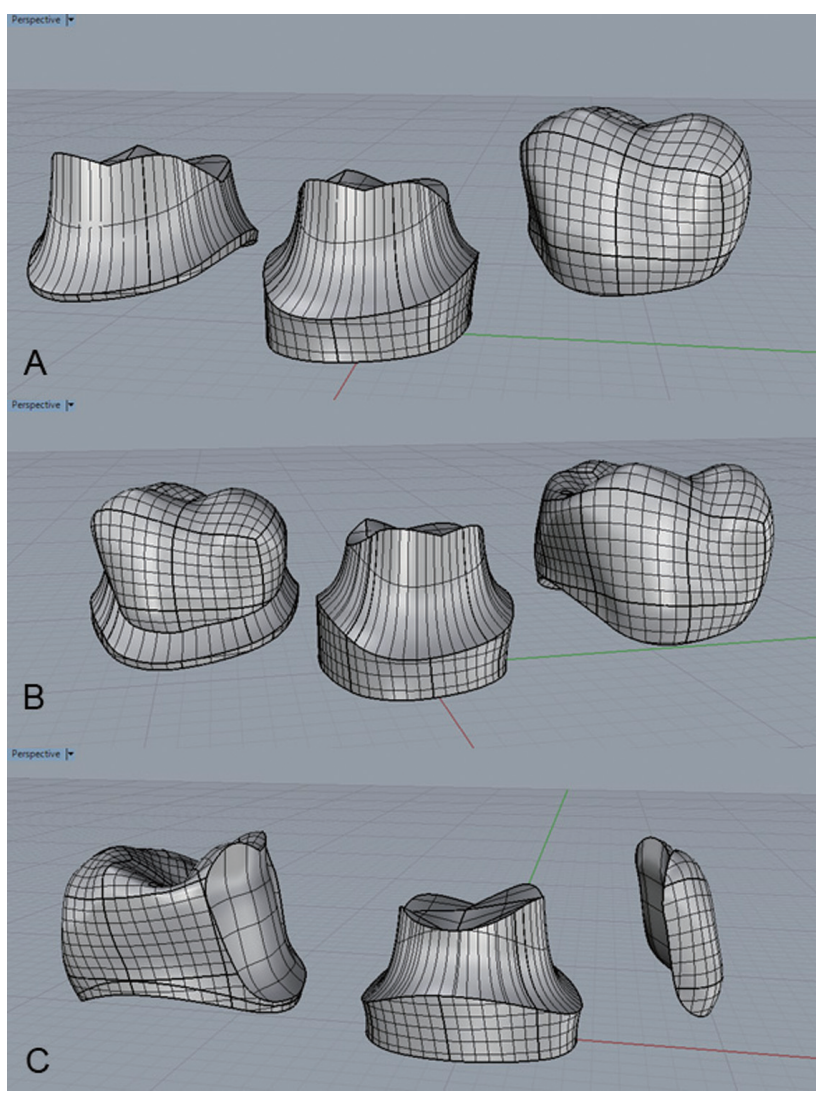

Fig. 1 Geometric models with differential coping designs. (A) a uniform thickness of $0.5 \mathrm{~mm}$ of the framework. (B) a cutback design. (C) a buccal reduction of the framework. 
joined in nodes. 47,205 respective 55,434 and 43,085 tetrahedral elements were generated for each model, connected in 80,720 nodes for the first model and in 93,924 and 72,002 nodes for the second and third one. Finite element calculations were carried out.

Since ceramic materials exhibit brittle behavior, the first principal stress criterion was adopted. First principal stress (omax) regions and values for three types of designs and various overpressing ceramic materials, in two layers (veneer layer and framework), were determined through 3D graphs and software output values.

In order to simulate the influence of different framework designs, the Young's module and Poisson's ratios were introduced: Young's modulus $(\mathrm{GPa}) 18$ for dentin, 69 (for leucit reinforced) respective 95 (for lithium disilicate) for veneering ceramics, and 205 for zirconia and Poisson's ratio 0.27 for dentin, 0.21 (for leucit reinforced) respective 0.23 (for lithium disilicate)

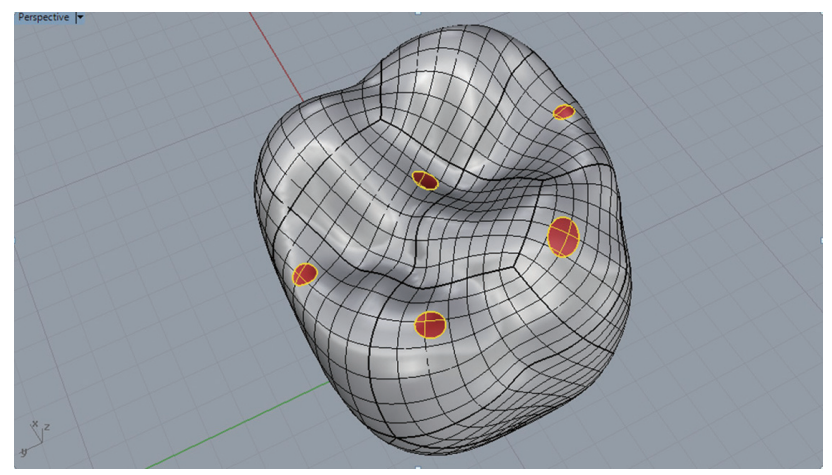

Fig. 2 Loading areas on the occlusal surface of the molar. for veneering ceramics, and 0.31 for zirconia.

To simulate physiological mastication behavior five loading areas were defined on the occlusal surface. Each defined loading area had a diameter of $0.5 \mathrm{~mm}$. A total force of $250 \mathrm{~N}$ was allocated to these areas as pressure load normal to the surfaces in each point (Fig. 2). The bottom of the abutment teeth model was fully constrained for all simulations.

A static structural analysis was performed to calculate the stress distribution for different designs using the computer-aided engineering software. The biomechanical behavior of all-ceramic systems based on stress criteria was evaluated using the maximum principle stress induced in such brittle materials.

\section{RESULTS}

Using FEA maximum principle stresses were recorded in the tooth structures and in the restoration for all the developed designs (Tables 1, 2 and Figs. 3, 4).

For the first two designs the values were higher in the veneers. There stresses were distributed around the contact areas with the antagonists. The values of the maximal principal stresses in the frameworks were higher for the design with uniform thickness. On the other hand the values and location of the maximal stresses represent areas of weakness and starting points for crack propagation. For the model with buccal veneer of the framework, maximal stress values are higher in the framework than for the other cases, but in the veneer are recorded the lowest stress values. The maximal stress values in the dentin are similar regardless of the restoration type.

Reported at the veneering material, the stress values are similar in the dentin. For the crowns veneers with lithium disilicate overpressed ceramics, the stress

Table 1 Maximum principal stresses in the tooth structures and in the restoration for the developed designs using leucitereinforced ceramics as veneering material

\begin{tabular}{lccc}
\hline \multicolumn{1}{c}{ Compound } & $\begin{array}{c}\text { Max. principal stress } \\
\text { in model 1 (MPa) }\end{array}$ & $\begin{array}{c}\text { Max. principal stress } \\
\text { in model 2 (MPa) }\end{array}$ & $\begin{array}{c}\text { Max. principal stress } \\
\text { in model 3 (MPa) }\end{array}$ \\
\hline Dentin & 2.70 & 2.52 & 2.27 \\
Zirconia framework & 30.74 & 28.03 & 42.54 \\
Veneering ceramics & 46.59 & 64.49 & 2.71 \\
\hline
\end{tabular}

Table 2 Maximum principal stresses in the tooth structures and in the restoration for the developed designs using lithium disilicate-reinforced ceramics as veneering material

\begin{tabular}{lccc}
\hline \multicolumn{1}{c}{ Compound } & $\begin{array}{c}\text { Max. principal stress } \\
\text { in model 1 (MPa) }\end{array}$ & $\begin{array}{c}\text { Max. principal stress } \\
\text { in model 2 (MPa) }\end{array}$ & $\begin{array}{c}\text { Max. principal stress } \\
\text { in model 3 (MPa) }\end{array}$ \\
\hline Dentin & 2.66 & 2.53 & 2.32 \\
Zirconia framework & 28.64 & 27.05 & 42.55 \\
Veneering ceramics & 43.05 & 58.92 & 3.48 \\
\hline
\end{tabular}



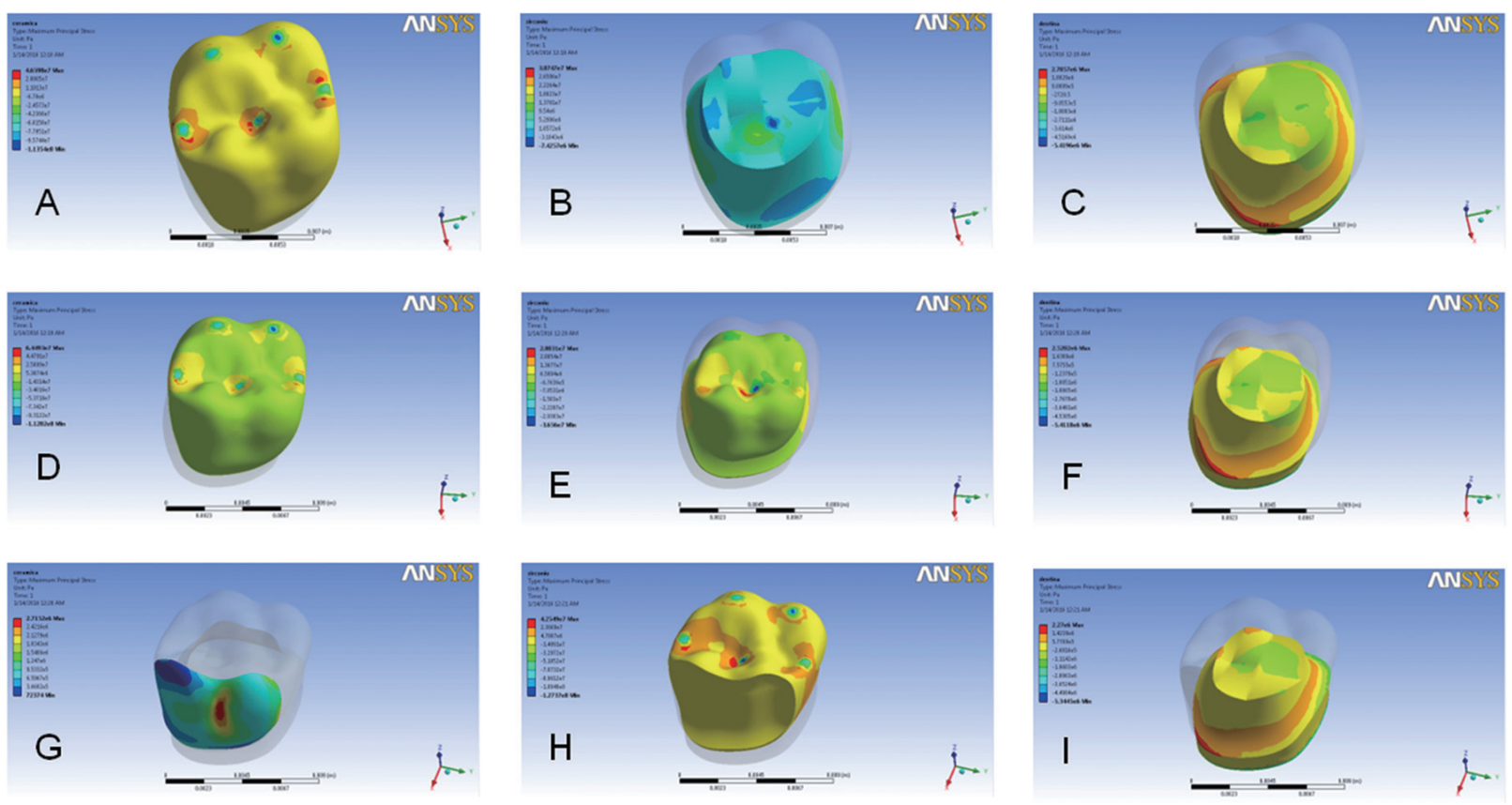

Fig. 3 Maximum principal stresses distribution in the restoration and in the tooth structures for the developed designs using leucite-reinforced ceramics as veneering material.

(A) in the veneering ceramics for the design with uniform thickness of the framework. (B) in the framework for the design with uniform thickness of the framework. (C) in the dentin for the design with uniform thickness of the framework. (D) in the veneering ceramics for the cut-back design of the framework. (E) in the framework for the cut-back design of the framework. (F) in the dentin for the cut-back design of the framework. $(G)$ in the veneering ceramics for the design with buccal reduction of the framework. (H) in the framework for the design with buccal reduction of the framework. (I) in the dentin for the design with buccal reduction of the framework.

values were lower both in the framework and in the veneer for the first two designs. For the last design, they were insignificant higher.

\section{DISCUSSION}

The hypothesis that the zirconia framework design and the veneering material may influence the biomechanical behavior of the restoration is accepted.

Because the strength values for lithium disilicate are higher than those for leucite reinforced ceramics (306 MPa compared to $106 \mathrm{MPa}$ ), the weaknesses of the crowns veneered with lithium disilicate are lower, but for all the designs the maximal values of the principal stresses are under the strength values of the materials.

Consequently, several studies assessed possibilities to reduce the probability of chipping of veneered zirconia frameworks (which occurs often in wear areas or areas where the occlusion has been adjusted), e.g., optimizing both firing protocol, the framework design, the fabrication process, and the use of pressed or CAD/CAM achieved veneer ceramics. Furthermore, CAD/CAM fabricated veneers could complete the digital workflow in the production of dental restorations s $^{1,12,18,29,30)}$.

Industrially produced ceramic blanks used for the fabrication of veneers show fewer faults compared to manually produced veneers. Thus, the fatigue behavior and the fracture strength are supposed to be superior in these materials compared to hand-layered ceramics. Porcelain-veneered restorations often chip and fracture from repeated occlusal loading, making fatigue studies relevant. Several in vitro and in vivo investigations reported suitable strength and mechanical performances of zirconia, compatible with clinical serviceability as a framework material. However, clinical results are not comparable, at the moment, with conventional metalceramic restorations, neither is there sufficient long-term data for validating the clinical potential of zirconia ${ }^{6}$.

Alternative materials and technologies may influence the biomechanical behavior of all-ceramic systems. Different studies ${ }^{2,12,31)}$ show that the material properties of pressed and CAD ceramics are superior compared to those of hand-layered feldspathic ceramics. An optimized firing protocol has shown to have a positive effect of the load to failure, but many technicians do not use optimized firing programs and many furnaces do not support this option and problems originating from this manufacturing mode resulted in the development of the presented new approaches ${ }^{30)}$.

Other experiments in the literature are focused on 

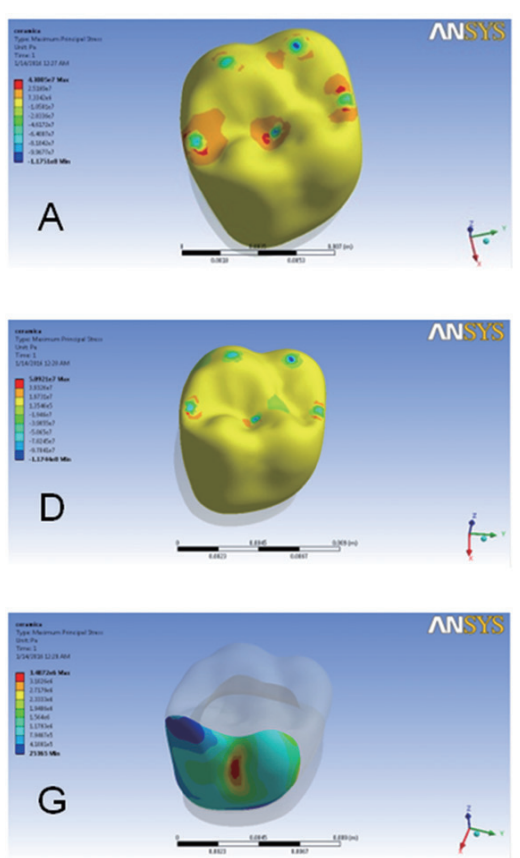
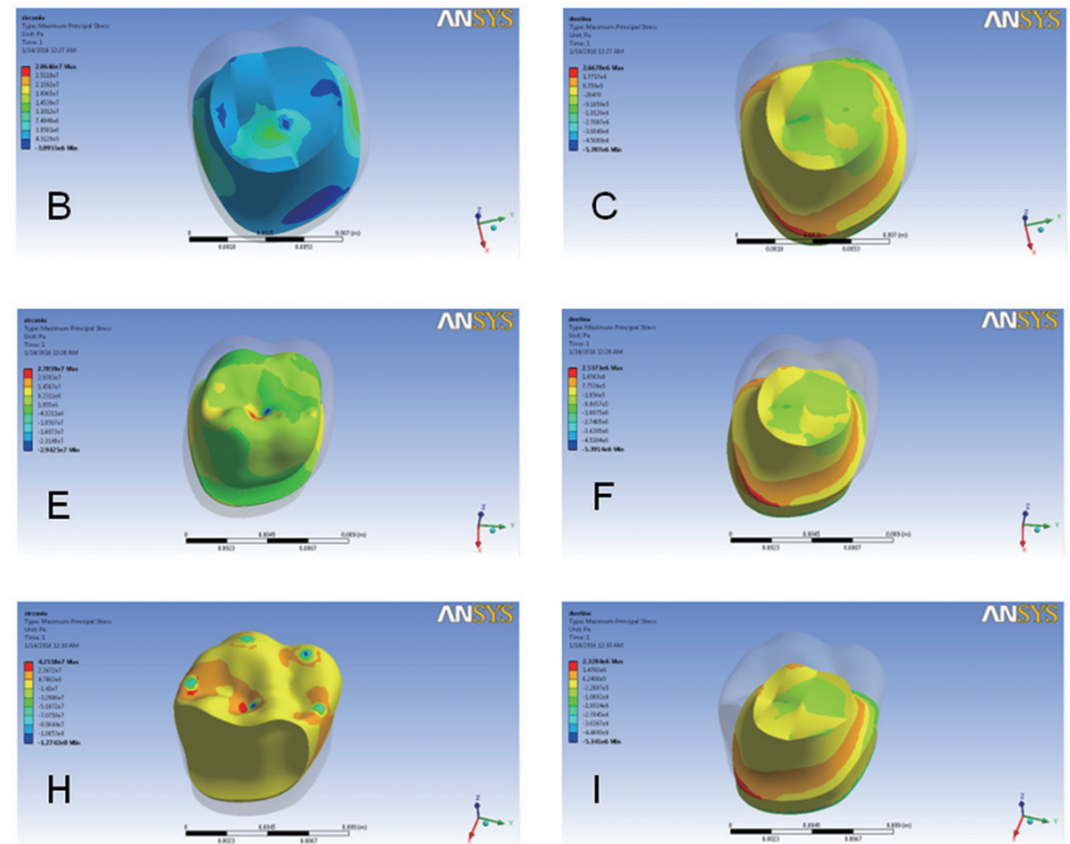

Fig. 4 Maximum principal stresses distribution in the restoration and in the tooth structures for the developed designs using lithium disilicate-reinforced ceramics as veneering material.

(A) in the veneering ceramics for the design with uniform thickness of the framework. (B) in the framework for the design with uniform thickness of the framework. (C) in the dentin for the design with uniform thickness of the framework. (D) in the veneering ceramics for the cut-back design of the framework. (E) in the framework for the cut-back design of the framework. (F) in the dentin for the cut-back design of the framework. $(\mathrm{G})$ in the veneering ceramics for the design with buccal reduction of the framework. $(\mathrm{H})$ in the framework for the design with buccal reduction of the framework. (I) in the dentin for the design with buccal reduction of the framework.

the design of zirconia-ceramic crowns. Some studies ${ }^{7,32-34)}$ described the customization of a milled zirconia coping based on anatomical parameters to provide even and controlled veneer thickness with the aim of decreasing cohesive veneer fracture. The zirconia core modification provided veneer support at the cusp tip and at marginal ridges. In contrast, substantially different veneers to core thickness ratios were observed with the standard core design. CAD software setting produces an even core thickness and an uneven veneer thickness at different cusp inclines, due to anatomical/occlusal constraints. Fatigue load induced flaws propagated through pressable and hand-layer veneering ceramics without being stopped or deflected by the zirconia core. Increased veneer thickness has been pointed to lead towards more extensive internal stress field within the veneering ceramic. The modification of the substructure providing anatomic support in the cusp area reduced the incidence of chipping at low load levels significantly. The thinner layer of the weak veneering porcelain was supported by the underlying zirconia material. In this study FEA show higher stresses in the veneers when the anatomical design of the framework was chosen, associated with a thinner veneer layer, and therefore the zirconia support is very important from biomechanical point of view.
As chipping occurred in all tested crowns irrespective of framework designs and veneering techniques cohesive veneer fracture seems to remain a problem in all-ceramic zirconia based restorations ${ }^{7)}$.

Other approaches have been attempted to improve the mechanical behavior of all ceramic crowns, including veneering ceramics with leucite reinforced microstructures as its improved fracture toughness may reduce chipping effect ${ }^{12)}$. They concluded that a reinforced ceramic veneering material is associated with lower principal stresses than lithium based ceramics, aspects outlined in the current study. Taking into account the fact that the fracture strength of reinforced materials is higher, fracture risk is reduced even further at this kind of ceramics. In addition, alternative veneering techniques such as CAD/CAM-fabricated veneers milled out of a high strength lithium disilicate material were described ${ }^{13)}$. Recently, a new idea of milling solid monolithic (full-contour) zirconia crowns has occurred ${ }^{35,36)}$.

It is obviously impossible for a computer simulation to include all of the factors encountered in the oral environment. The applicability of FEA results to oral conditions depends upon, among other factors, the similarity between the shape, dimensions, material 
data, load application of the models, and the natural teeth $^{37)}$. To provide general guidelines for zirconia based restoration fabrication and a basis for predicting their performance, further studies are required to elucidate the effect of different parameters and stress states within the framework and veneering ceramics. The research was focused on the framework design and type of the veneering material, but using the same technological procedure (only hot-overpressing of ceramics, not sintering). Therefore for yet other aspects were not analyzed in the comparison.

In future work studies may be to diversified to evaluate more important parameters involved in the behavior of zirconia-ceramics dental crowns achieved also by other alternative technologies.

\section{CONCLUSION}

Different framework designs for zirconia-overpressed ceramics restorations can be chosen in order to provide adequate support for the veneering material. Three type of zircconia framework designs were taken into the study, veneered with two types of hot-pressed ceramics, in order to test the hypothesis that the framework design and veneering material may influence the biomechanical behavior of zirconia-ceramic crowns. Recent advances in CAD/CAM technology and simulation platforms, namely the finite element analysis (FEA) were used for the investigations. The hypothesis was accepted.

\section{ACKNOWLEDGMENT}

This work was supported by a grant of the Romanian National Authority for Scientific Research and Innovation CNCS-UEFISCDI, project number PN-IIRU-TE-2014-4-0476.

\section{REFERENCES}

1) Schmitter M, Mueller D, Rues S. Chipping behaviour of allceramic crowns with zirconia framework and CAD/CAM manufactured veneer. J Dent 2012; 40: 154-162.

2) Guess PC, Zavanelli RA, Silva NR, Bonfante EA, Coelho PG, Thompson VP. Monolithic CAD/CAM lithium disilicate versus veneered Y-TZP crowns: comparison of failure modes and reliability after fatigue. Int J Prosthodont 2010; 23: 434442.

3) Silva NR, Bonfante EA, Zavanelli RA, Thompson VP, Ferencz JL, Coelho PG. Reliability of metalloceramic and zirconia based ceramic crowns. J Dent Res 2010; 89: 1051-1056.

4) Heintze SD, Rousson V. Survival of zirconia- and metalsupported fixed dental prostheses: a systematic review. Int J Prosthodont 2010; 23: 493-502.

5) Pjetursson BE, Sailer I, Zwahlen M, Hammerle CH. A systematic review of the survival and complication rates of all-ceramic and metal-ceramic reconstructions after an observation period of at least 3 years. Part I. Single crowns. Clin Implant Dent Relat Res 2007; 18: 73-85.

6) Zarone F, Russo S, Sorrentino R. From porcelain-fused-tometal to zirconia: clinical and experimental considerations. Dent Mater 2011; 27: 83-96.

7) Guess PC, Bonfante EA, Silva NR, Coelho PG, Thompson VP. Effect of core design and veneering technique on damage and reliability of Y-TZP-supported crowns. Dent Mater 2013; 29: 307-316.

8) Bonfante EA, Sailer I, Silva NR, Thompson VP, Dianne Rekow E, Coelho PG. Failure modes of Y-TZP crowns at different cusp inclines. J Dent 2010; 38: 707-712.

9) Marchack B, Futatsuki Y, Marchack C, White S. Customization of milled zirconia copings for all-ceramic crowns: a clinical report. J Prosthet Dent 2008; 99: 163-173.

10) Pogoncheff CM, Duff RE. Use of zirconia collar to prevent interproximal porcelain fracture: a clinical report. J Prosthet Dent 2010; 104: 77-79.

11) Aboushelib MN, Kleverlaan CJ, Feilzer AJ. Microtensile bond strength of different components of core veneered allceramic restorations. Part II. Zirconia veneering ceramics. Dent Mater 2006; 22: 857-863.

12) Christensen RP, Ploeger BJ. A clinical comparison of zirconia, metal and alumina fixed-prosthesis frameworks veneered with layered or pressed ceramic: a three-year report. J Am Dent Assoc 2010; 141: 1317-1329.

13) Beuer F, Edelhoff D, Gernet W, Sorensen JA. Three-year clinical prospective evaluation of zirconia-based posterior fixed dental prostheses (FDPs). Clin Oral Investig 2009; 13: 445-451.

14) Guess PC, Zhang Y, Thompson VP. Effect of veneering techniques on damage and reliability of Y-TZP trilayers. Eur J Esthet Dent 2009; 4: 262-276.

15) Beuer F, Schweiger J, Eichberger M, Kappert HF, Gernet W, Edelhoff D. High-strength CAD/CAM-fabricated veneering material sintered to zirconia copings - a new fabrication mode for all-ceramic restorations. Dent Mater 2009; 25: 121128.

16) Tsalouchou E, Cattell MJ, Knowles JC, Pittayachawan $\mathrm{P}$, Mcdonald A. Fatigue and fracture properties of yttria partially stabilized zirconia crown systems. Dent Mater 2007; 24: 308-318.

17) Wolfart S, Harder S, Eschbach S, Lehmann F, Kern M. Fouryear clinical results of fixed dental prostheses with zirconia substructures (Cercon): end abutments vs. cantilever design. Eur J Oral Sci 2009; 117: 741-749.

18) Rosentritt M, Kolbeck C, Handel G, Schneider-Feyrer $\mathrm{S}$, Behr M. Influence of the fabrication process on the in vitro performance of fixed dental prostheses with zirconia substructures. Clin Oral Investig 2011; 15: 1007-1012.

19) Rafferty BT, Janal MN, Zavanelli RA, Silva NR, Rekow ED, Thompson VP, Coelho PG. Design features of a threedimensional molar crown and related maximum principal stress. A finite element model study. Dent Mater 2010; 26 : 156-163.

20) Hu J, Dai N, Bao Y, Gu W, Ma J, Zhang F. Effect of different coping designs on all-ceramic crown stress distribution: a finite element analysis. Dent Mater 2013; 29: 291-298.

21) Oyar P, Ulusoy M, Eskitaşçioğlu G. Finite element analysis of stress distribution in ceramic crowns fabricated with different tooth preparation designs. J Prosthet Dent 2014; 112: 871877.

22) Shahrbaf S, Van Noort R, Mirzakouchaki B, Ghassemieh E. Effect of the crown design and interface lute parameters on the stress-state of a machined crown-tooth system: a finite element analysis. Dent Mater 2013; 29: 123-131.

23) Erdemir A, Guess TM, Halloran J, Tadepalli SC, Morrison TM. Considerations for reporting finite element analysis studies in biomechanics. J Biomech 2012; 45: 625-633.

24) Porojan L, Topală F, Porojan S. Stress analyses applications on all-ceramic crowns with different designs. WSEAS Trans Biol Biomed 2016; 13: 40-44.

25) https://www.physicsforums.com/threads/vonmises-stress-vsmaximum-principle-stress.206854/

26) http://www.learnengineering.org/2012/12/theories-of-failure. html 
27) http://web.mae.ufl.edu/nkim/eas4200c/VonMises Criterion. pdf

28) De Aza AH, Chevalier J, Fantozzi G, Schehl M, Torrecillas R. Crack growth resistance of alumina, zirconia and zirconia toughened alumina ceramics for joint prostheses. Biomaterials 2002; 23: 937-945.

29) Rosentritt M, Steiger D, BEhr M, Handel G, Kolbeck C. Influence of substructure design and spacer settings on the in vitro performance of molar zirconia crowns. J Dent 2009; 37: 978-983.

30) Rues S, Kroger E, Muller D, Schmitter M. Effect of firing protocols on cohesive failure of all-ceramic crowns. J Dent 2010; 38: 987-994

31) Buso L, Oliveira-Júnior OB, Hiroshi Fujiy F, Leão Lombardo GH, Ramalho Sarmento H, Campos F, Assunção Souza RO. Biaxial flexural strength of CAD/CAM ceramics. Minerva Stomatol 2011; 60: 311-319.

32) Raigrodski AJ, Chiche GJ, Potiket N, Hochstedler JL, Mohamed SE, Billiot S, Mercante DE. The efficacy of posterior three-unit zirconium-oxide-based ceramic fixed partial dental prostheses: a prospective clinical pilot study. J Prosthet Dent 2006; 96: 237-244.

33) Sailer I, Gottnerb J, Kanelb S, Hammerle CH. Randomized controlled clinical trial of zirconia-ceramic and metal-ceramic posterior fixed dental prostheses: a 3-year follow-up. Int J Prosthodont 2009; 22: 553-560.

34) Sailer I, Feher A, Filser F, Gauckler LJ, Luthy H, Hammerle $\mathrm{CH}$. Five-year clinical results of zirconia frameworks for posterior fixed partial dentures. Int J Prosthodont 2007; 20: 383-388.

35) http://www.dentalaegis.com/idt/2011/01/, Moving to Monolithic. Inside Dental Technol 2011; 2: 70-71.

36) Kim JW, Kim JH, Thompson VP, Zhang Y. Sliding contact fatigue damage in layered ceramic structures. J Dent Res 2007; 86: 1046-1050.

37) Dejak B, Młotkowski A, Langot C. Three-dimensional finite element analysis of molars with thin-walled prosthetic crowns made of various materials. Dent Mater 2012; 28: 433-441. 